\title{
Implementation of a Flexible Manufacturing System in a production cell of the automotive industry: decision and choice
}

\author{
Miguel Afonso Sellitto ${ }^{\mathrm{a} *}$ (D), Vagner Gerhardt Mancio ${ }^{\mathrm{a}}$ \\ aUniversidade do Vale do Rio dos Sinos - UNISINOS, São Leopoldo, RS, Brasil \\ *sellitto@unisinos.br
}

\begin{abstract}
Paper aims: The purpose is to decide on the technology for the implementation of an FMS in a manufacturing cell that produces the coil for starting engines in a company of the Brazilian automotive industry.

Originality: The mixed use of structured methods to support a semi-structured decision-making problem.

Research method: The qualitative-quantitative modeling, relying on four competitive priorities of the manufacturing, cost, quality, flexibility, and delivery. The method considered three technological alternatives $\mathrm{A} 1$, a ladder-type layout, conveyor and pneumatic devices, A2, an open field layout and automatic guided vehicles, and A3, a robot-centered layout and robotic arms.
\end{abstract}

Main findings: Two different methods arrived at the same conclusion. The best alternative is A3, which is also better than doing nothing.

Implications for theory and practice: The complete description of a real-world case, embracing the decision-making process and the final choice and the difficulties faced by a decision analyst in supporting practitioners in solving a complex problem.

Keywords

Flexible Manufacturing System. Automation. Manufacturing strategy. Industrial robots. Analytical hierarchy process.

How to cite: Sellitto, M. A., \& Mancio. V. G. (2019). Implementation of a Flexible Manufacturing System in a production cell of the automotive industry: decision and choice. Production, 29, e20180092. https://doi.org/10.1590/0103-6513.20180092

Received: Oct. 10, 2018; Accepted: Apr. 29, 2019.

\section{Introduction}

In early markets, cost reduction and quality improvement were the main requirements imposed on companies and supply chains to survive and prosper in the business arena. Therefore, companies attempted to reduce cost and simultaneously improve the quality, focusing their efforts on the manufacturing activity (Zhang et al., 2009). More recently, flexibility and dependability emerged as critical dimensions of competition. Again, companies relied on manufacturing to acquire competitivity, turning the business arena into a much more complex, uncertain, and turbulent environment (Rudd et al., 2008).

Aiming at new markets, manufacturing companies introduced Flexible Manufacturing Systems (FMS) to break the classic trade-off between dependability and quality. FMS reduce labor and consequently process variability, improving the quality of the product. At the same time, FMS provide multiple production routes that overcome maintenance liabilities and queuing conflicts, increasing the reliability of deliveries (Tracey et al., 1999) and the dependability of the manufacturing (Prakash et al., 2017). Summarizing, FMS’s increase the overall productivity, improve the final product quality, and at the same time reduce vulnerabilities due to unexpected variations in the volume, the mix, and the due dates of the orders (Rezaie \& Ostadi, 2007). 
An FMS is a manufacturing system with the capacity to react to unexpected, relevant changes in volume, mix, and due date of orders (Tao et al., 2017). FMS's provide eight types of operational flexibilities (Kumar \& Mishra, 2017). For this study, three are most relevant. Machine flexibility is the ability to produce new products or new combinations of current products. Routing flexibility is the ability to use multiple routes to produce the same item or multiple devices to perform the same operation. Volume flexibility is the ability to change the order quantity without changing the cost, primarily by virtually instantaneous set-up procedures (Stevenson \& Spring, 2007).

The implementation of FMS requires high capital investment. Moreover, the presence of qualitative, strategic issues makes the techniques centered on economic engineering insufficient to perform feasibility studies (Prakash et al., 2017). Combined methods, including qualitative evaluations and multicriteria approaches, should be used to justify the adoption of FMS (Wabalickis, 1988). Summarizing, cost reduction appraised by economical engineering, or quality improvement, assessed by statistical techniques, are not sufficient to support decisions regarding FMS.

The assessment of the feasibility of the implementation of FMS must include at last four criteria or strategic dimensions: cost, quality, flexibility, and dependability (Boyer, 1998). The productivity provided by the cost reduction and the quality provided by the reduction in the variability are no longer the exclusive relevant factors in implementing an FMS. The ability to react to unexpected changes and the dependability can also provide significant strategic gains, usually more important than cost reduction or quality improvement (Kakati \& Dhar, 1991). Many studies (Handfield \& Pagell, 1995; Monaham \& Smunt, 1987; Parsaei et al., 1988) showed that financial arguments cannot appraise the strategic benefits provided by the technology, resulting in incomplete conclusion on the effectiveness of an FMS.

The purpose of this article is to decide on the technology for the implementation of an FMS in a manufacturing cell that produces coils for starting engines in a company of the Brazilian automotive industry. The research question is how to evaluate technological options for the implementation of an FMS? The research method is quantitative modeling. The specific objectives are to choose and prioritize the most important competitive dimension for the case, to construct and evaluate options for the choice, and to prioritize the options for the final decision. The result is valid only for the studied cell, but the method can be applied to other, similar manufacturing cells. The main contribution of the article is the complete description of a real-world case, embracing the totality of the decision-making process conducted by the company and achieving a final choice. The main novelty is the use of two different ways to transform the preferences of the decision-makers into a technological choice. Both methods gave the same results, reinforcing the conclusion. This article is based upon a conference paper (to be disclosed later). It is substantially different ( $60 \%)$, with full results, a discussion, and a more elaborated conclusion.

The remainder of the article is organized as follows. Section 2 presents a literature review on FMS. Section 3 presents the research methodology. Section 4 presents the results. Section 5 discusses and summarizes the findings. Section 6 concludes the article and suggests directions for future research.

\section{FMS: definition and characteristics}

An FMS is an arrangement of automated processing machines interconnected by conveyors and material handling systems. The manufacturing process in an FMS requires a combination of workstations and possibilities of technological paths, provided by the material handling system and inspected by an automatic inspection unit. Approved parts exit the FMS; rejected parts must return to further processing (Shivanand et al., 2006). An FMS can also be understood as an automated manufacturing cell, composed of a set of workstations interconnected by automated transfer and handling units, as well as storage systems, controlled by a distributed industrial computing system. An automated manufacturing cell can process various types of parts simultaneously in various workstations that adjust themselves automatically to unexpected variations in the mix and in the volume of the orders (Rose-Anderssen et al., 2017).

Cellular layouts are the best-suited layouts for FMS, due to their ability to economically process intermediate volume and variety of items (Deif \& ElMaraghy, 2017). For high variety and low volume, a combination of job-shop system and discrete automation is better. For low variety and large volumes, a combination of a flow-shop system and transfer automation is better. Finally, in intermediate situations, a better solution combines cellular manufacturing and FMS (Shivanand et al., 2006). Figure 1 illustrates the relationship between volume, variety, layout, and automation. 


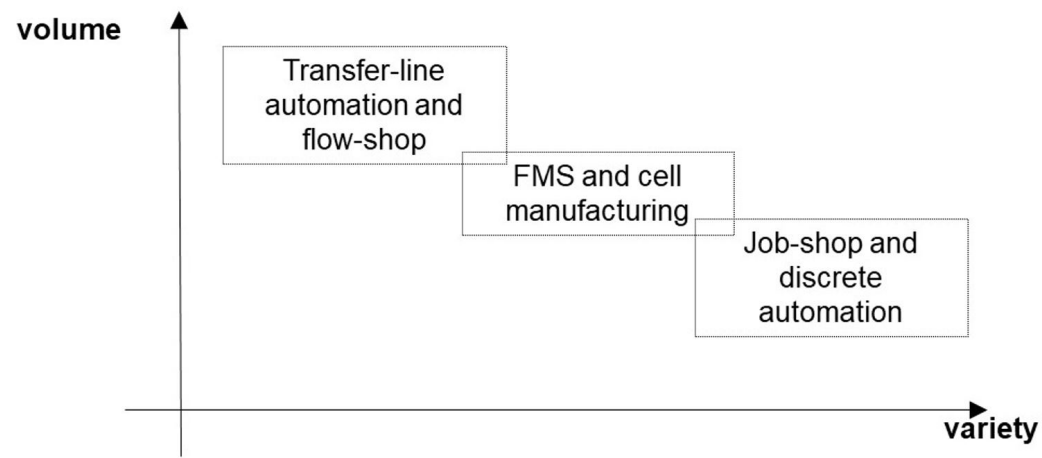

Figure 1. Relationships between automation, layout, volume, and variety.

An FMS implementation can rely on five types of layouts (Shivanand et al., 2006): (i) line type, in which the workstations are sequentially positioned and allow only direct flow of materials, loaded and unload at separate, extreme points; (ii) loop type, in which the workstations are positioned in cellular, U-shaped format, and allows only the circulation of the material, loaded and unloaded in the same point; (iii) ladder type layout, in which the workstations are pairwise positioned and allows the material to circulate between and around, loaded and unloaded in the same point; (iv) open field layout type, in which AGV freely moves across the workstations, transferring the material loaded and unloaded at the same point; and (v) robot-centered layout type, in which the working stations are positioned around one or more robots, which allows any kind of movement of the material.

\subsection{Components of an FMS}

A typical FMS consists of computer numeric control (CNC) machine tools, interconnected by automated material handling, storage systems, automated inspection, and controlled by an integrated computer system.

A CNC machine tool is an industrial device that shapes or machines metal or other types of rigid materials. The main operations are cutting, drilling, boring, grinding, milling, etching, or shearing the material (Browne et al., 1984). A machine tool integrates three essential elements: the machine and controllers, the part to be processed, and the tool. Their basic elements are the machine base, parts handling devices, tools and automatic tool changer, drive units and controls, and logic-programmable commands and sensors (Mahmood et al., 2017). FMS workstations include at least one CNC machine tool equipped with a tool magazine, performing multiple sequential operations (milling, drilling, etching, etc.). The setup is automatic and virtually instantaneous, requiring minimal or no human attention. The tool magazine temporarily storage the tools, which provide rapid die exchange and a high level of efficiency (Baykasoğlu \& Ozsoydan, 2017).

Material handling in FMS requires pallets and containers, transported in Automated Guided Vehicle Systems (AGVS) or on conveyors. AGVS are unmanned vehicles that follow a guided path in automated facilities. AGVS reduce labor cost, accidents, and increase the speed and accuracy of transportation (Gothwal \& Raj, 2018). The main techniques used alone or combined in AGVS are underground cables, allowing only fixed trajectories; wireless command that allows multiple trajectories; optical command and painted lines that allow modifying the trajectory; wireless command, optical encoders, or scanners that allows tracking the trajectory; wireless orientation based on tracking algorithms; and wireless orientation referenced by beacons at the floor (Sabattini et al., 2015). The main functionalities of AGVS are the orientation of the vehicle, the optimization of the route, the traffic management to avoid collisions and to load and unload materials (Martínez-Barberá \& Herrero-Pérez, 2010). Complementing AVGS, conveyors move standard loads by fixed paths formed by rollers, curved rollers, casters, mats, sloping mats, chains, and suitable combinations that provide horizontal and vertical transportation and direction changes (Rahman et al., 2017).

Robotic arms can also serve as material handling systems. An industrial robot is a programmable, general-purpose machine with anthropomorphic characteristics, such as arm resemblance, response to sensory stimuli, communication with other machines, and decision-making ability (Martínez-Barberá \& Herrero-Pérez, 2010). The essential components of a robot are the mechanical manipulator, the actuators that convert electrical, hydraulic, or pneumatic energy into mechanical power for movement, the sensors that measure position, speed, force, or torque, the control unit, and the power unit (Yamamoto et al., 2016). The main tasks performed by robots in manufacturing are welding, handling, painting, assembling, and palletizing (Wang et al., 2017). 
In FMS's, loads are handled by automated storage and retrieval systems (AS/RS), composed of storage structures, stacker cranes and transelevators. Storage structures require profiles, shelves and lifting equipment, suitable for receiving and storing standardized loads, accommodated in pallets and containers. Transelevators are mobile structures for high-speed horizontal and vertical movement that access the storage installation to store and retrieve intermediate loads, not yet finished or not yet claimed by the client (Guasch et al., 2011). An important research problem is the optimization of routes of AVGS and transelevators and the occupation of the storage shelves in FMS.

Finally, in FMS, automated inspection units perform the final quality inspection, prior to the delivery. Automated inspection uses automated devices and software tools to perform quality verifications in parameters, such as dimension and shape of parts. Its primary advantage is to implement a faster and more reliable inspection procedure that those conducted by human inspectors. Usually, the CNC machine tool accomplishes the automated inspection simultaneously with the final stages of the machining process, which prevents feeding the next process with faulty parts (Bi \& Kang, 2014).

\section{The strategic role of FMS: multicriteriality}

Deciding on FMS requires two steps. In the first, the decision team should define all the feasible technological alternatives. In the second, the team prioritizes the alternatives, considering their performance under multiple criteria (Loch et al., 2001). Cost reduction is not the unique criteria to judge the feasibility of the implementation of an FMS's (Wabalickis, 1988). FMS also reduce set-up times, increase production flexibility (Kakati \& Dhar, 1991), reduce lead times for new products development, reduce dues dates, increase the dependability of orders, and improve product quality (Karsak \& Kuzgunkaya, 2002).

Most of these strategic benefits are intangible and hardly estimated by purely economic methods, such as the internal return rate or net present value. As the criteria may vary and their importance is subjective, depending on the perception of decision-makers on the impact on the strategic drivers, the choice of the technology for an FMS can be considered a semi-structured problem. Such type of problem requires a structured approach to support decision makers (Yazdani et al., 2017). Therefore, we applied a multicriteria method to support the decision.

Multicriteria decisions are abundantly found in industrial management. The decision-making process may embed conflicting objectives and multiple alternatives, requiring group decision. The consequences of the choices are uncertain and embed risks not always clear to all the decision-makers (Myint \& Tabucanon, 1994; (Ghasemzadeh \& Archer, 2000). The number of criteria and comparisons influence the quality of the decision (Rezaei, 2015). Few criteria can lead to the absence of significant aspects; too many criteria can divert attention from essential points. One way to rationalize the number of criteria is to discard those indifferent to all the alternatives (Liesio et al., 2007). Another way is to reduce the number of comparisons between criteria (Rezaei, 2015). Another issue is the independence between criteria. Two criteria are mutually independent when variations in one criterion do not affect the other. If the criteria are objective and independent, multicriteria evaluation is essential in the decision-making process (Vargas, 1982).

Multicriteria methods are classified according to the principles of two schools, the American and the European schools. The American school considers that the alternatives of a problem must be clear, objective, and independent to be fully comparable. The European school admits that solutions may not be comparable or objectively separable, assuming ambiguous assessments (Zavadskas \& Turskis, 2011). This study relies only on the American school and considers the AHP (Analytic Hierarchy Process). AHP is the most cited and most applied method found in the literature (Javid et al., 2014; Achimugu et al., 2014; Bulut et al., 2015) and is suitable to deal with modeling of production, logistics, and manufacturing problems (Tzeng \& Huang, 2012). The literature widely describes AHP. We only underscore that the decision-making criteria are pairwise compared, relying on a fundamental scale, regarding the ability to solving the decision problem. The output of this step is a value function that helps to calculate the merit and to rank the alternatives. The AHP also calculates a consistency ratio $\mathrm{CR}$, the probability that the choice was based on random, non-rational criteria. If $\mathrm{CR}>0.1$ the decision-maker must repeat the judgment (Saaty, 1983). Table 1 shows the fundamental scale that supports the pairwise comparison, essential to AHP (Saaty, 2008).

This study considers four criteria, the so-called strategic dimensions in manufacturing competition, cost, quality, flexibility, and delivery. Particular cases may eventually consider other competitive dimensions that may contain elements also observed in the four primitive dimensions (Ward et al., 1998). For example, innovation can be a competitive priority, representing the ability of manufacturing to rapidly introduce new products and processes (Leong et al., 1990). But this capacity can also be considered a sub-dimension of flexibility. Likewise, dependability is the probability of delivering an order at the right time, correct quantity, and sufficient quality. It can be a competitive dimension (Roh et al., 2014), but it can also be a sub-dimension of delivery (Drohomeretski et al., 2014). 
Table 1. Fundamental scale (Saaty, 2008).

\begin{tabular}{|c|c|c|}
\hline Intensity of importance & Definition & Explanation \\
\hline 1 & Equal Importance & Two activities contribute equally to the objective \\
\hline 3 & Moderate importance & Experience and judgment slightly favor one activity over another \\
\hline 5 & Strong importance & Experience and judgment strongly favor one activity over another \\
\hline 7 & Very strong importance & $\begin{array}{l}\text { An activity is favored very strongly over another; its dominance } \\
\text { demonstrated in practice }\end{array}$ \\
\hline 9 & Extreme importance & $\begin{array}{l}\text { The evidence favoring one activity over another is of the highest } \\
\text { possible order of affirmation }\end{array}$ \\
\hline $2,4,6,8$ & Intermediate values & Used for graduation in slightly differences \\
\hline Reciprocals & $\begin{array}{l}\text { An assignment to } i \text { compared with } j \text { implies } \\
\text { the reciprocal to } j \text { compared with } i\end{array}$ & \\
\hline
\end{tabular}

To unify the conceptual basis, it is important to recall the characteristics of the four primitive dimensions of the manufacturing strategy here considered (Ward et al., 1998). The cost includes the initial cost necessary for the implementation of the FMS and innovations along the useful life, the variable cost that is proportional to the amount of production (for example, raw material and energy), and the fixed cost that do not depends on the production rate (for example, preventive maintenance activities). Quality relies on intrinsic characteristics of the product, the reliability of the product and the process, conformity with standards, useful lifetime, low variability in the process, and service level. Delivery relies on the adequacy of due dates; accuracy, reliability, and speed of deliveries; and availability of those items included in quick response policies. Flexibility relies on eight competitive sub-dimensions (Beach et al., 2000): machine (rapid set-up), process (to make the same product by different processes), mix (to quickly vary the mix), routing (alternative routes to the same mix), volume (to economically vary the lot size), expansion (to economically vary the production rate), operational (to interchange the ordering of several operations), and production (to interchange the families of parts produced by the FMS).

\section{The research}

The studied manufacturing cell requires ten operators and fourteen workstations to produce coils. Figure 2 shows the exploded view of the starter motor, in which the coil is the component number 4 . The other components are bearings and housing (1), pinion assembly (2), armature (3), brushes (5), and solenoid (6).

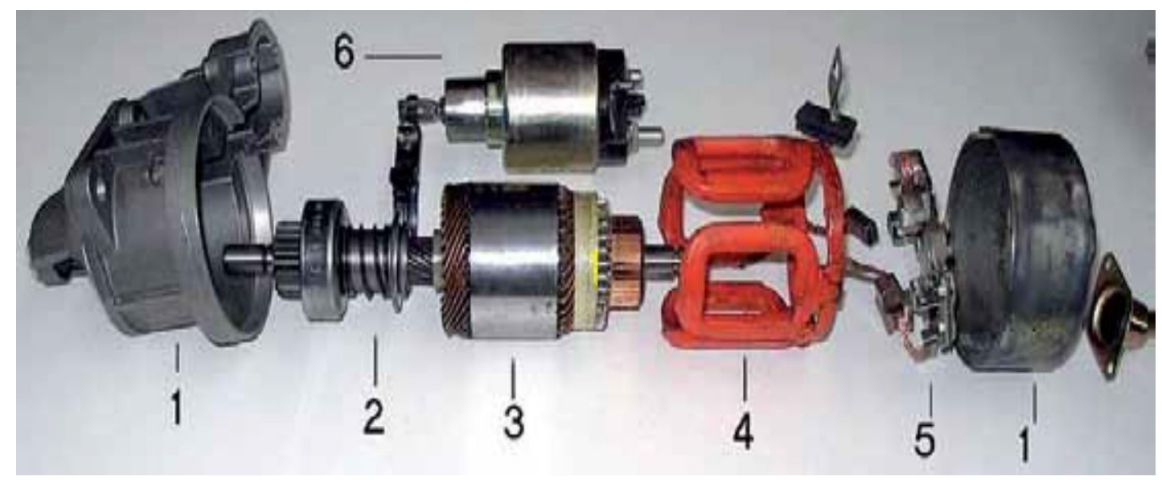

Figure 2. Exploded view of the starting engine.

The layout is U-shaped so an operator can serve several workstations. A production line parallel to the cell supplies a pre-assembled part. Seven operators serve inside the cell, one operator serves exclusively the workstation 4 (WS4), and one operator serves WS 5 and WS 6. WS 14 holds the final inspection. One operator supplies the operation and dispatches the final product. Figure 3 shows the current layout of the manufacturing cell.

The company produces five types of starting engine to meet local orders with a planning horizon of thirty weeks. The demand follows a random pattern. The production planning support reevaluating the demand by up to $20 \%$ each week. Figure 4 shows a typical period of ten weeks of aggregate demand. The $R^{2}$ coefficient close to zero indicates that, in the period, the demand oscillated around a fixed average, which reinforces that the demand has a random behavior. 


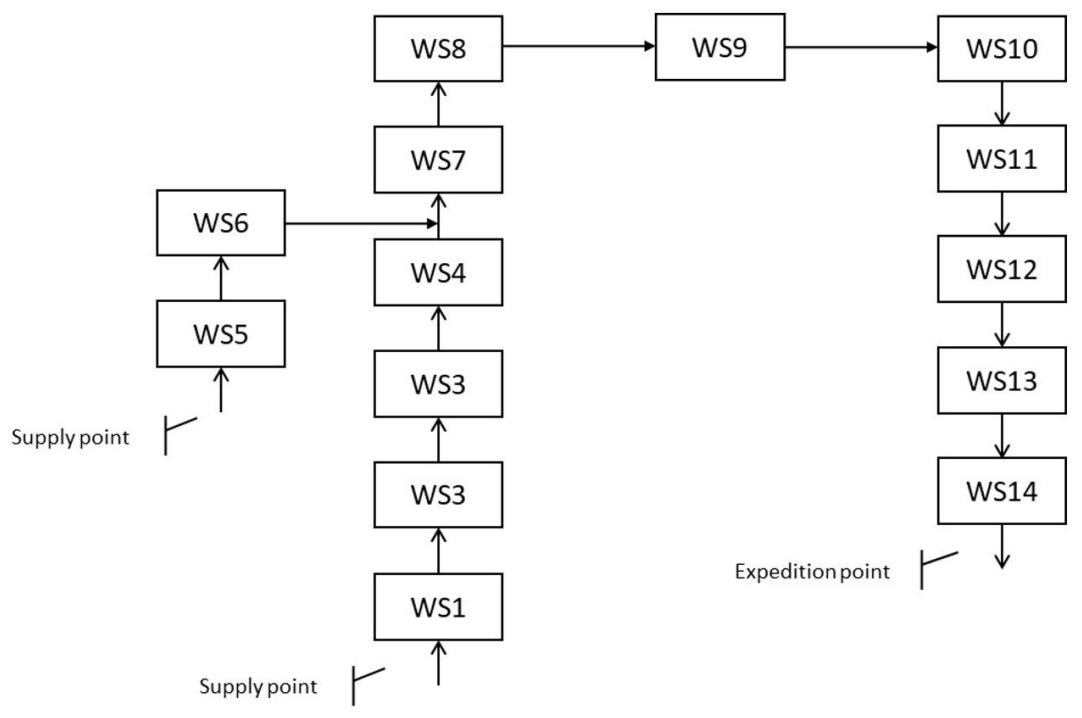

Figure 3. Current layout of the manufacturing cell.

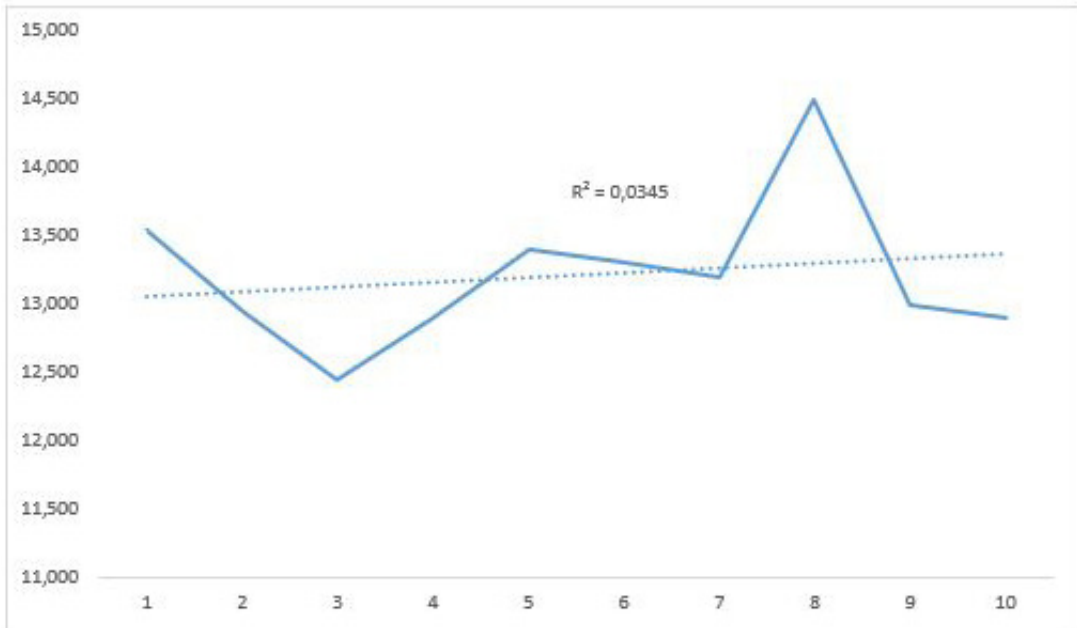

Figure 4. The pattern of the aggregate demand.

The methodology is:

(i) Six managers (quality, production, process, maintenance, logistics, and industrial engineering) prioritized four criteria (cost, quality, delivery, flexibility) according to their contribution to face competition in the industry (first specific objective);

(ii) Supported by specialists, the engineering team of the company prepared three technological alternatives for the implementation of FMS in the cell. The managers studied the alternatives and analyzed their influence on each criterion (second specific objective);

(iii) Supported by the researchers, the managers individually produced six preference matrices prioritizing the competitive dimensions. The researchers analyzed the matrices, received feedback from the managers, and proposed a final value function (based on the mean preference) that expresses the priority given to the competitive dimensions; and

(iv) The researchers used the value function to evaluate the merit of the alternatives, employing two methods, pair-wise comparison among alternatives and qualitative evaluation of single alternatives. Both arrived at the same result, which reinforces the final decision (third specific objective). 
Some considerations about validity are worthwhile. Validity is the extent to which a measurement reflects only the studied object, without interferences from other sources (Gibbert et al., 2008). Usually, studies shall assure internal, external and construct validity (Voss et al., 2002). In this study, internal validity refers to the correct appropriation of the observed variables or the assurance that the results of the evaluation are not due to external factors. It is necessary to avoid interference from spurious variables or behaviors (Sellitto, 2018). To ensure internal validity, this study used triangulation (multiple sources in the evaluation), participants' feedback (participants reviewed the findings), and a logic model (a tree-like structure) for the evaluation. Triangulation and feedback assure accuracy and the logic model correctly allocated the variables and assured the absence of spurious factors.

External validity refers to the ability of generalization to different contexts. However, due to the peculiarities of the manufacturing cell, generalizing to other cells is not a major purpose of this study. Eventually, other applications can use the same methodology.

Construct validity refers to the ability of the study to capture the essentials of the object (Bagozzi et al., 1991), i.e., the extent the study investigates what it claims to investigate (Gibbert et al., 2008). The study considered the construct validity in the review phase when assumed that the four dimensions appraise the ability of the manufacturing to compete in a supply chain, according to the literature (Ward et al., 1998).

\section{Results}

\subsection{Evaluation of the competitive dimensions}

The managers involved with the cell operation evaluated qualitatively the four criteria according to two scales, to increase reliability $[4=$ more important, $\ldots, 1=$ less important $]$ and $[1 / 1=$ more important, $\ldots, 1 / 4=$ less important]. A previous study (Sellitto et al., 2012) states that judging the criteria in a descending importance order (most important first), rather than random order, usually produces a lower consistency ratio. To assure internal validity, the managers evaluated the alternatives alone, without mutual interferences and without the presence of directors, who could influence the judgment. Both scales provide the same result. The managers considered the quality as the more important dimension, followed by delivery, cost, and flexibility. Table 2 shows the results.

Table 2. Evaluation of the criteria by the managers.

\begin{tabular}{|c|c|c|c|c|c|c|c|c|}
\hline \multirow{2}{*}{ Manager } & \multicolumn{4}{|c|}{ First scale } & \multicolumn{4}{|c|}{ Second scale } \\
\hline & Cost & Quality & Flexibility & Delivery & Cost & Quality & Flexibility & Delivery \\
\hline 1 & 2 & 4 & 1 & 3 & $1 / 3$ & 1 & $1 / 4$ & $1 / 2$ \\
\hline 2 & 1 & 4 & 2 & 3 & $1 / 4$ & 1 & $1 / 3$ & $1 / 2$ \\
\hline 3 & 2 & 4 & 1 & 3 & $1 / 3$ & 1 & $1 / 4$ & $1 / 2$ \\
\hline 4 & 2 & 3 & 1 & 4 & $1 / 3$ & $1 / 2$ & $1 / 4$ & 1 \\
\hline 5 & 2 & 4 & 1 & 3 & $1 / 3$ & 1 & $1 / 4$ & $1 / 2$ \\
\hline 6 & 2 & 4 & 1 & 3 & $1 / 3$ & 1 & $1 / 4$ & $1 / 2$ \\
\hline Total & 11 & 23 & 7 & 19 & 2 & $51 / 2$ & $14 / 7$ & $31 / 2$ \\
\hline Order & Third & First & Fourth & Second & Third & First & Fourth & Second \\
\hline
\end{tabular}

\subsection{Three alternatives}

The first alternative A1 considers a ladder-type layout. The transportation is by conveyor and pallets with movement in a single direction. Pneumatic devices feed and remove material from the machines and the loading and unloading (LO/UL) of materials to and from the system occur at different points. Four WS include CNC machines and automated inspection, central tool magazine, supported by a temporary storage area (TSA) AS/RS with capacity for four hours of production. The sequencing and control are by $\mathrm{PLC}$ and the interconnection is by FieldBus standard.

The second alternative A2 considers an open-field layout. The transportation is by AGV and containers with free movement. An AGV feeds and removes material from the machines and the loading and unloading (LO/UL) of materials to and from the system occur at the same point. Four WS include CNC machines and automated inspection, individual tool magazines, supported by a carousel temporary storage area with capacity for eight hours of production. The sequencing and control are by PLC and the interconnection is wireless. 
The third alternative A3 considers a robot-centered layout. The transportation is by robotic arms (RB) and containers with free movement. A robotic arms feed and remove material from the machines by a circular conveyor and the loading and unloading (LO/UL) of materials to and from the system occur at the same point. Four WS include CNC machines and automated inspection, central tool magazine, supported by a TSA is AS/RS with capacity for two hours. The sequencing and control are by PLC and the interconnection is by FieldBus standard.

The six managers evaluated the pros and cons of the alternatives.

The main advantages of $\mathrm{A} 1$ are: (i) multiple orders executed simultaneously; (ii) low cost, mainly due to pneumatic devices; and (iii) low set-up time due to the centralized tool magazine. The main disadvantages are (i) delays due to the single direction of the transport system; (ii) more maintenance, mainly due to pneumatic systems; and (iii) greater variability due to pneumatic systems and the centralized tool magazine. The main advantages of A2 are: (i) more flexibility in processing parts; (ii) more accuracy due to AGVs; and (iii) instant set-up due to individual magazines. The main disadvantages are (i) excessive dependence on the AGVS, whose autonomy is only two hours; (ii) higher cost; and (iii) possible conflicts in loading and unloading material at the same point. The main advantages of $\mathrm{A} 3$ are: (i) low cost; (ii) more flexibility and precision due to robots; and (iii) reduced set-up time due to the central tool magazine. The main disadvantages are (i) small storage capacity; (ii) possible delays for the lack of availability of robots; and (iii) potential conflicts in loading and unloading material by the same point.

Figure 5 shows the three alternatives. Table 3 synthesizes the differences.

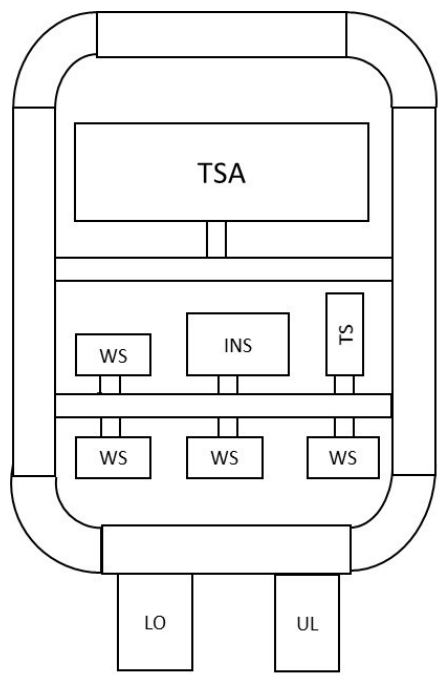

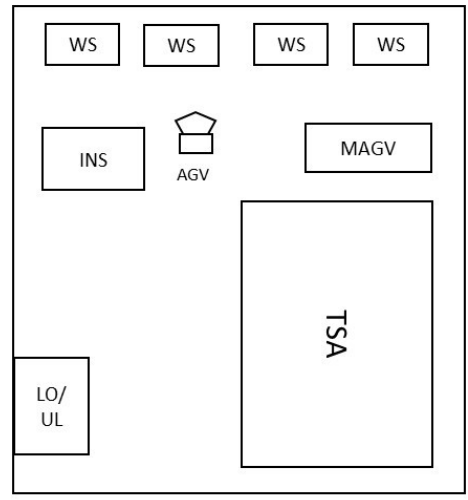

A2

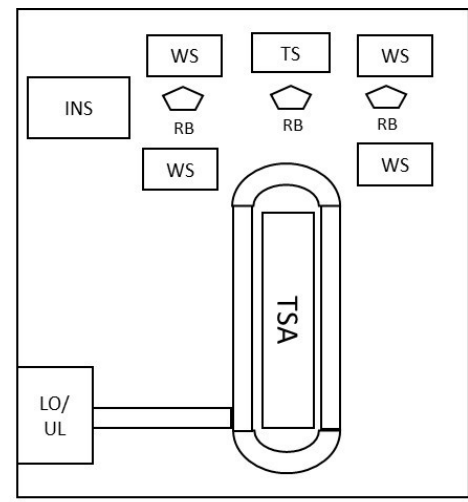

A3

A1

Figure 5. The alternatives for the decision. TSA: Temporary Storage Area; WS: Working Station; INS: Inspection Station; TS: Tool Storage; LO/UL: Load/Unload material to/from the system; MAGV: Service Station for AGV; RB: Robotic Arm; AGV: Automatic Guided Vehicle.

Table 3. Differences among the alternatives.

\begin{tabular}{llll}
\hline \multicolumn{1}{c}{ Feature } & \multicolumn{1}{c}{ A1 } & \multicolumn{1}{c}{ A2 } \\
\hline Layout & Ladder & Open Field & Robot centered \\
Materials movement & Conveyor & AGV & Robotic Arm \\
Materials handling & Pneumatic & AGV & Robotic Arm \\
Network communication & Field Bus & Wireless & Field Bus \\
Tool storage & Centralized & Individualized & Centralized \\
Materials storage & AS/RS & Carrousel & AS/RS, circular conveyor \\
Particular advantages & Flexibility in processing orders, low & Flexibility in processing parts, & Low cost, flexibility in processing \\
& cost, low set-up time. & accuracy, instant set-up. & parts, low set-up time \\
Particular disadvantages & Delays in processing orders, & Lower reliability due to the excessive & Lower storage capacity, delays in \\
& complexity in maintenance & dependence on the AGVs, higher cost, processing orders, delay in load and \\
& procedures, greater variability. & delays in load and unload. & unload. \\
\hline
\end{tabular}




\subsection{The priority vector and the value function}

Researchers and internal experts supported the managers in the use of AHP. Due to the descending order, the application quickly converged to low $C R$ (average $=0.05$, maximum $=0.07$ ), as expected. The researchers compiled the results, presented to the managers, and helped them to refine evaluations, until achieving a final acceptance as a valid, rational preference structure. As the judgment of manager 5 consistently differed from the others, it was removed. The feedback process helped to assure the internal validity of the findings. It is not meaningful to show all the six individual matrices. Therefore, Table 4 synthesizes the results showing the validated priorities assigned by the managers, as well as the average and standard deviation (sd) of the priorities.

The last row of the table is the priority vector of the competitive dimensions to be used in further calculations. Given the assumed standard deviations, the probability of an inversion in the top of the ranking (i.e., the highest priority is delivery, instead of quality) is $2.9 \%$, which is an acceptable value and reinforces the internal validity. The best technological alternative will be the one that will maximize the value function given by Equation 1 .

$$
\text { Value }=[0.39 \text { quality }]+[0.31 \text { delivery }]+[0.22 \text { cost }]+[0.08 \text { flexibility }]
$$

Table 4. Competitive priorities for the manufacturing.

\begin{tabular}{|c|c|c|c|c|c|}
\hline Manager & Cost $\%$ & Quality \% & Flexibility $\%$ & Delivery \% & Sum $\%$ \\
\hline 1 & 15 & 39 & 10 & 37 & 100 \\
\hline 2 & 27 & 41 & 5 & 27 & 100 \\
\hline 3 & 15 & 39 & 7 & 39 & 100 \\
\hline 4 & 15 & 39 & 7 & 39 & 100 \\
\hline 6 & 36 & 38 & 13 & 13 & 100 \\
\hline $\mathrm{sd}$ & 4.0 & 0.5 & 1.3 & 4.3 & \\
\hline Average & 22 & 39 & 8 & 31 & \\
\hline
\end{tabular}

\subsection{Analysis of the alternatives}

To calculate the merits of the alternatives, the six managers made pairwise comparisons among the possible future scenarios, according to their judgment on the capacity of the technological alternatives to positively influence the four competitive dimensions. For the pairwise comparison, each manager answered the following question: How do you classify $\mathrm{A} i$ in comparison with $\mathrm{A} j$ regarding the ability to influence the competitive dimension $k$ ? Researchers supported and gave feedback along the entire process of judgment. Each manager produced four matrices, totalizing 24 matrices. All CRs were less than 0.1 . The average value of the $24 \mathrm{CR}$ is less than 0.01. It is not meaningful to show all the matrices. Table 5 synthesizes the results showing only the average and the standard deviation (SD) of the priorities assigned by the managers to the alternatives regarding the competitive dimensions.

Table 5. Priorities of the alternatives in the competitive dimensions.

\begin{tabular}{|c|c|c|c|c|c|c|c|c|}
\hline \multirow{2}{*}{ Alternative } & \multicolumn{2}{|c|}{ Quality } & \multicolumn{2}{|c|}{ Delivery } & \multicolumn{2}{|c|}{ Cost } & \multicolumn{2}{|c|}{ Flexibility } \\
\hline & Average $\%$ & SD \% & Average $\%$ & SD $\%$ & Average $\%$ & SD \% & Average $\%$ & SD \% \\
\hline $\mathrm{A} 1$ & 20 & 6.2 & 25 & 10.5 & 37 & 9.7 & 38 & 10.5 \\
\hline A2 & 41 & 7.7 & 31 & 9.7 & 35 & 8.8 & 18 & 5.8 \\
\hline A3 & 39 & 9.2 & 44 & 8.8 & 28 & 10.5 & 44 & 9.8 \\
\hline sum & 100 & & 100 & & 100 & & 100 & \\
\hline
\end{tabular}

Some standard deviations are high, reflecting the lack of consensus among the decision-makers about the gain of competitivity. This lack of consensus reinforces that the problem is unstructured and confirms the need for a multicriteria method. Taking into account the average values, Table 5 provides a set of vectors that can explain the influence of the alternatives on the competitive dimensions and how the potential of each dimension is captured by each alternative. For example, in the first column, the vector [20\%, 41\%, 39\%] represents how, i.e., in what proportions, the potential of the quality dimension is distributed among the three alternatives. In the first row, the vector $[20 \%, 25 \%, 37 \%, 38 \%]$ represents how, i.e., in what intensity, the first alternative capture the potential of the quality, delivery, cost, and flexibility dimensions, respectively. 
The next step is the calculation of percentage merits for A1, A2, and A3. The calculation considers the vector of priorities of the four dimensions [quality $=39 \%$; delivery $=31 \%$; cost $=22 \%$; and flexibility $=8 \%$ ] and the vector of the intensities of the alternative. The percentage merit of an alternative is the linear combination of the two vectors. Table 6 presents the percentage merits of the three alternatives. Their sum is 100\%, as expected.

Table 6. Evaluation of the alternatives.

\begin{tabular}{ccc}
\hline Alternative & Calculation & Merit \\
\hline A1 & $(0.20 \times 0.39)+(0.25 \times 0.31)+(0.37 \times 0.22)+(0.38 \times 0.08)$ & 0.27 \\
A2 & $(0.41 \times 0.39)+(0.31 \times 0.31)+(0.35 \times 0.22)+(0.18 \times 0.08)$ & 0.35 \\
A3 & $(0.39 \times 0.39)+(0.44 \times 0.31)+(0.27 \times 0.22)+(0.44 \times 0.08)$ & 0.38 \\
\hline
\end{tabular}

To verify the calculation and assure internal validity, the study used an alternative method. The second method for the calculation employed qualitative evaluations. The managers appraised the effectiveness of each alternative in capturing the competitive potential of each dimension. Given $A i$ and dimension $j$, each manager answered the following question: in your opinion, how do you classify the contribution of A $i$ to competitive dimension $j$ ? The answer was quantified according to a scale: $[1=$ very high contribution; $0.75=$ high contribution; 0.5 = fair contribution; $0.25=$ low contribution; and $0=$ very low contribution]. Table 7 shows the appraisal.

Table 7. The contribution of the alternatives to the competitive dimensions.

\begin{tabular}{|c|c|c|c|c|c|c|c|c|c|c|c|c|}
\hline \multirow{2}{*}{ manager } & \multicolumn{3}{|c|}{ Quality } & \multicolumn{3}{|c|}{ Delivery } & \multicolumn{3}{|c|}{ Cost } & \multicolumn{3}{|c|}{ Flexibility } \\
\hline & $\mathrm{A} 1$ & $\mathrm{~A} 2$ & A3 & $\mathrm{A} 1$ & $\mathrm{~A} 2$ & A3 & $\mathrm{A} 1$ & $\mathrm{~A} 2$ & A3 & $\mathrm{A} 1$ & $\mathrm{~A} 2$ & A3 \\
\hline 1 & 0.75 & 0.75 & 0.75 & 0.75 & 1 & 1 & 0.75 & 0.75 & 0.75 & 0.75 & 0.75 & 1 \\
\hline 2 & 0.75 & 1 & 1 & 0.75 & 0.75 & 1 & 0.75 & 0.75 & 0.5 & 1 & 1 & 1 \\
\hline 3 & 0.75 & 0.75 & 0.5 & 0.5 & 0.75 & 1 & 0.75 & 0.5 & 0.5 & 1 & 1 & 1 \\
\hline 4 & 1 & 1 & 1 & 0.75 & 0.75 & 1 & 0.75 & 0.5 & 0.5 & 0.75 & 0.75 & 0.75 \\
\hline 5 & 0.75 & 0.75 & 1 & 0.75 & 0.75 & 1 & 0.75 & 0.75 & 0.75 & 1 & 1 & 1 \\
\hline 6 & 0.75 & 1 & 1 & 0.5 & 1 & 1 & 0.5 & 0.5 & 0.5 & 0.75 & 1 & 1 \\
\hline Average & 0.79 & 0.88 & 0.92 & 0.67 & 0.83 & 1.00 & 0.71 & 0.63 & 0.58 & 0.88 & 0.92 & 0.96 \\
\hline SD & 0.04 & 0.04 & 0.08 & 0.04 & 0.04 & 0.00 & 0.04 & 0.04 & 0.04 & 0.04 & 0.04 & 0.04 \\
\hline
\end{tabular}

Only the influence of A3 in delivery obtained full consensus. The managers failed in reaching consensus in the rest of the evaluations, facing some amount of uncertainties in the judgment. However, this uncertainty is small, represented by the small standard deviations calculated, which reinforces the internal validity of the result. To facilitate the understanding of the rationale, Table 8 retains only the average values and repeats the priority vector.

Table 8. Average values and priority vector.

\begin{tabular}{ccccc}
\hline & Quality & Delivery & Cost & Flexibility \\
\hline A1 & 0.79 & 0.67 & 0.71 & 0.88 \\
A2 & 0.88 & 0.83 & 0.63 & 0.92 \\
A3 & 0.92 & 1 & 0.58 & 0.96 \\
Priority & 0.39 & 0.31 & 0.22 & 0.08 \\
\hline
\end{tabular}

Referring to Table 8, by linear combinations between the evaluation vector and the priority vector, Table 9 calculates and normalizes the merits of the alternatives.

In both Tables ( 6 and 9), A3 is the best choice, followed by A2 and A1.

Table 9. A second evaluation of the alternatives.

\begin{tabular}{cccc}
\hline Alternative & Calculation & Merit & Normalized merit \% \\
\hline A1 & $(0.79 \times 0.39)+(0.67 \times 0.31)+(0.71 \times 0.22)+(0.88 \times 0.08)$ & 0.74 & 31 \\
A2 & $(0.88 \times 0.39)+(0.83 \times 0.31)+(0.63 \times 0.22)+(0.92 \times 0.08)$ & 0.81 & 33 \\
A3 & $(0.92 \times 0.39)+(1.00 \times 0.31)+(0.58 \times 0.22)+(0.96 \times 0.08)$ & 0.87 & 36 \\
\hline
\end{tabular}




\section{Discussion}

The discussion includes two issues, a qualitative analysis of the choices and a quantitative comparison between the best alternative A3 with the current situation.

Referring to Table 4, A1 achieved the best performance in cost, A2 in quality, and A3 in delivery and also in flexibility. Some trade-offs are remarkable. A1 is good at cost, but poor in quality; A2 is good in quality, but poor in flexibility; A3 is good in delivery and flexibility, but poor in cost. The managers commented on those trade-offs.

The good performance of $\mathrm{A} 1$ in cost is due to conveyors and pneumatic systems, which operation and maintenance costs are substantially lower than the others. However, the low accuracy of pallets and pneumatic devices increases the variability of the operations, causing the poor performance of A1 in quality. The good performance of A2 in quality is due to the high accuracy and reliability of the AGVS. However, the AGVS is also responsible for the poor performance of A2 in flexibility. The AGVS requires larger lot sizes to operate efficiently, producing a higher work-in-process that increases the average lead-time and reduces the capacity to absorb unexpected changes in the production mix. The good performance of A3 in delivery and in flexibility is due to the high reliability and redundancy provided by the combination of the robotic arm and the circular conveyor. The redundancy decreases internal queues, reduces lead-time and provides a high degree of flexibility. However, the handling system needs additional, expressive preventive maintenance efforts, jeopardizing the overall cost. Additionally, the low capacity of storage (two hours) requires lower lot sizes, increasing the operational cost. Both weaknesses cause poor performance in the cost dimension.

The managers also commented about the major influences of the technological elements in the dimensions. The low accuracy of pneumatic devices and the circular conveyor is the main responsible for poor performance in quality. The good accuracy and low failure rate of AGVS are the main responsible for good performance in quality. The low reliability of pallets and pneumatic devices are the main responsible for poor performance in delivery. The high reliability provided by the redundancy of robotic arms is the main responsible for good performance in delivery. Conveyors, pallets, and pneumatic systems are the main responsible for good performance in cost. Redundant robotic arms and the circular conveyor are the main responsible for poor performance in cost. The low lot size needed and the consequent low work-in-process and lead-time produced by robotic arms and the circular conveyor is the main responsible for good performance in flexibility. The large lot size required and consequent high work-in-process and lead-time produced by the AGVS is the main responsible for poor performance in flexibility.

Finally, the discussion compares A3 and the current situation A0. In a judgment, one choice is to do nothing, meaning that reaching the best alternative does not assure an advantageous implementation. As this final comparison is not the main purpose of the study, we limit the analysis to a single, qualitative evaluation, using the same scale that produced the results of Table 9. The managers applied to the current situation. Table 10 compares the evaluations of A3 with A0.

Table 10. Comparison of A3 with A0.

\begin{tabular}{cccc}
\hline Dimension & Priority $\%$ & A3 & A0 \\
\hline Quality & 39 & 0.92 & 0.54 \\
Delivery & 31 & 1.00 & 0.37 \\
Cost & 22 & 0.58 & 0.71 \\
Flexibility & 8 & 0.96 & 0.54 \\
Merit & & 0.87 & 0.52 \\
SD & & 0.10 & 0.11 \\
\hline
\end{tabular}

The merit line results from the sum of products between the priority vector and A3 (second and third column) and the priority vector and AO (second and fourth columns). Given the standard deviations, the probability of inversion is $1 \%$, which is acceptable and confirms the conclusion. Therefore, the study concludes that A3, besides being the best choice, is better than no choice.

\section{Final remarks}

The purpose of this article was to decide on the technology for the implementation of an FMS in a manufacturing cell that produces coils for starting engines in a company of the Brazilian automotive industry. The research question was how to evaluate technological options for the implementation of an FMS? An 
engineering team, supported by vendors, proposed three alternatives $A 1, A 2$, and $A 3$. As none is better than others in all dimensions, it was necessary to develop a value function to support the decision process. The final choice is A3, verified by two methods. Therefore, the answer to the research question is the proposed method for the calculation of the merits of technological alternatives.

The study opens room for further research, the use of other multicriteria methods and competitive dimensions and the inclusion of managers of companies that develop and sell integrated technological solutions for industrial automation and FMS implementations. Many times, vendors are not aware of the capacity of their solutions to influence in the competitivity of their clients. Such integration could also benefit the manufacturing, as vendors could develop solutions more suitable to specific requirements of the manufacturing companies to face the competition in the industry. A final suggestion is the replications of the study in other industries that also use FMS, as the electronics industry, the furniture industry, or the packaging fabrication industry. Other industries, possibly, require different competitive dimensions, opening new perspectives about decision and choice on implementations of FMS in manufacturing.

\section{References}

Achimugu, P., Selamat, A., lbrahim, R., \& Mahrin, M. (2014). A systematic literature review of software requirements prioritization research. Information and Software Technology, 56(6), 568-585. http://dx.doi.org/10.1016/j.infsof.2014.02.001.

Bagozzi, R., Yi, Y., \& Phillips, L. (1991). Assessing construct validity in organizational research. Administrative Science Quarterly, 36(3), 421-458. http://dx.doi.org/10.2307/2393203.

Baykasoğlu, A., \& Ozsoydan, F. (2017). Minimizing tool switching and indexing times with tool duplications in automatic machines. The International Journal of Advanced Manufacturing Technology, 89(5-8), 1775-1789. http://dx.doi.org/10.1007/s00170-016-9194-z.

Beach, R., Muhlemann, A., Price, D., Paterson, A., \& Sharp, J. (2000). A review of manufacturing flexibility. European Journal of Operational Research, 122(1), 41-57. http://dx.doi.org/10.1016/S0377-2217(99)00062-4.

$\mathrm{Bi}, \mathrm{Z}$., \& Kang, B. (2014). Sensing and responding to the changes of geometric surfaces in flexible manufacturing and assembly. Enterprise Information Systems, 8(2), 225-245. http://dx.doi.org/10.1080/17517575.2012.654826.

Boyer, K. (1998). Longitudinal linkages between intended and realized operations strategies. International Journal of Operations \& Production Management, 18(4), 356-373. http://dx.doi.org/10.1108/01443579810199739.

Browne, J., Dubois, D., Rathmill, K., Sethi, S., \& Stecke, K. (1984). Classification of flexible manufacturing systems. The FMS Magazine, 2(1), 114-116.

Bulut, E., Duru, O., \& Koçak, G. (2015). Rotational priority investigation in fuzzy analytic hierarchy process design: An empirical study on the marine engine selection problem. Applied Mathematical Modelling, 39(2), 913-923. http://dx.doi.org/10.1016/j.apm.2014.07.018.

Deif, A., \& ElMaraghy, H. (2017). Variety and volume dynamic management for value creation in changeable manufacturing systems. International Journal of Production Research, 55(5), 1516-1529. http://dx.doi.org/10.1080/00207543.2016.1222088.

Drohomeretski, E., Gouvea da Costa, S. E., Pinheiro de Lima, E., \& Garbuio, P. A. R. (2014). Lean, Six Sigma and Lean Six Sigma: an analysis based on operations strategy. International Journal of Production Research, 52(3), 804-824. http://dx.doi.org/10.1080/0 0207543.2013.842015.

Ghasemzadeh, F. \& Archer, N. (2000). Project portfolio selection through decision support. Decision Support Systems, 29, 73-88. http:// dx.doi.org/10.1016/S0167-9236(00)00065-8.

Gibbert, M., Ruigrok, W., \& Wicki, B. (2008). What passes as a rigorous case study? Strategic Management Journal, 29(13), 1465-1474. http://dx.doi.org/10.1002/smj.722.

Gothwal, S., \& Raj, T. (2018). Optimisation of AGVs path layout in flexible manufacturing system using 0-1 linear integer programming International Journal of Process Management and Benchmarking, 8(2), 182-205. http://dx.doi.org/10.1504/1JPMB.2018.090796.

Guasch, A., Piera, M., \& Figueras, J. (2011). Automatic warehouse modelling and simulation. International Journal of Simulation \& Process Modelling, 6(4), 288-296. http://dx.doi.org/10.1504/IJSPM.2011.048008.

Handfield, R., \& Pagell, M. (1995). An analysis of the diffusion of flexible manufacturing systems. International Journal of Production Economics, 39(3), 243-253. http://dx.doi.org/10.1016/0925-5273(95)00026-K.

Javid, R., Nejat, A., \& Hayhoe, K. (2014). Selection of C02 mitigation strategies for road transportation in the United States using a multi-criteria approach. Renewable \& Sustainable Energy Reviews, 38(8), 960-972. http://dx.doi.org/10.1016/j.rser.2014.07.005.

Kakati, M., \& Dhar, U. (1991). Investment justification in flexible manufacturing systems. Engineering Costs and Production Economics, 21(3), 203-209. http://dx.doi.org/10.1016/0167-188X(91)90001-1.

Karsak, E., \& Kuzgunkaya, O. (2002). A fuzzy multiple objective programming approach for the selection of a flexible manufacturing system. International Journal of Production Economics, 79(1), 101-111. http://dx.doi.org/10.1016/S0925-5273(00)00157-2.

Kumar, R., \& Mishra, M. (2017). Manufacturing and supply chain flexibility: an integrated viewpoint. International Journal of Services and Operations Management, 27(3), 384-407. http://dx.doi.org/10.1504/1JSOM.2017.084447.

Leong, G., Snyder, D., \& Ward, P. (1990). Research in the process and content of manufacturing strategy. Omega, 18(2), 109-122. http://dx.doi.org/10.1016/0305-0483(90)90058-H.

Liesio, J., Mild, P., \& Salo, A. (2007). Preference programming for robust portfolio modeling and project selection. European Journal of Operational Research, 181(3), 1488-1505. http://dx.doi.org/10.1016/j.ejor.2005.12.041.

Loch, C., Pich, M., Terwiesch, C., \& Urbschat, M. (2001). Selecting R\&D projects at BMW: a case study of adopting mathematical programming models. IEEE Transactions on Engineering Management, 48(1), 70-80. http://dx.doi.org/10.1109/17.913167. 
Mahmood, K., Karaulova, T., Otto, T., \& Shevtshenko, E. (2017). Performance Analysis of a Flexible Manufacturing System (FMS). Procedia CIRP, 63(1), 424-429. http://dx.doi.org/10.1016/j.procir.2017.03.123.

Martínez-Barberá, H., \& Herrero-Pérez, D. (2010). Autonomous navigation of an automated guided vehicle in industrial environments. Robotics and Computer-integrated Manufacturing, 26(4), 296-311. http://dx.doi.org/10.1016/j.rcim.2009.10.003.

Monaham, G. E., \& Smunt, T. L. (1987). A multilevel decision support system for the financial justification of automated flexible manufacturing systems. Interfaces, 17(1), 29-40. http://dx.doi.org/10.1287/inte.17.6.29.

Myint, S., \& Tabucanon, M. (1994). A multiple-criteria approach to machine selection for flexible manufacturing systems. International Journal of Production Economics, 33(1), 121-131. http://dx.doi.org/10.1016/0925-5273(94)90125-2.

Parsaei, H., Karwowski, W., Wilhelm, M., \& Walsh, A. (1988). A methodology for economic justification of flexible manufacturing systems. Computers \& Industrial Engineering, 15(1), 117-122. http://dx.doi.org/10.1016/0360-8352(88)90073-3.

Prakash, R., Singhal, S., \& Agarwal, A. (2017). Modelling manufacturing system effectiveness: an integration of analytical hierarchy process and linear programming. International Journal of Intelligent Enterprise, 4(3), 227-242. http://dx.doi.org/10.1504/1JlE.2017.087627.

Rahman, A., Muhamad, E., Abdullah, S., Rahman, M., Osman, M., Mohamad, N., \& Noridan, N. (2017). A concept of physical reconfigurable conveyor system. Journal of Advanced Manufacturing Technology, 11(1), 29-36.

Rezaei, J. (2015). Best-worst multi-criteria decision-making method. Omega, 53(1), 49-57. http://dx.doi.org/10.1016/j.omega.2014.11.009.

Rezaie, K., \& Ostadi, B. (2007). A mathematical model for optimal and phased implementation of flexible manufacturing systems. Applied Mathematics and Computation, 184(2), 729-736. http://dx.doi.org/10.1016/j.amc.2006.05.179.

Roh, J., Hong, P., \& Min, H. (2014). Implementation of a responsive supply chain strategy in global complexity: the case of manufacturing firms. International Journal of Production Economics, 14711), 198-210. http://dx.doi.org/10.1016/j.jpe.2013.04.013.

Rose-Anderssen, C., Baldwin, J., \& Ridgway, K. (2017). Manufacturing systematics and cladistics: state of the art and generic classification. Journal of Manufacturing Technology Management, 28(5), 655-685. http://dx.doi.org/10.1108/JMTM-08-2016-0115.

Rudd, J., Greenley, G., Beatson, A., \& Lings, 1. (2008). Strategic planning and performance: extending the debate. Journal of Business Research, 61(1), 99-108. http://dx.doi.org/10.1016/j.jbusres.2007.06.014.

Saaty, T. (1983). Priority setting in complex problems. IEEE Transactions on Engineering Management, 30(1), 140-155. http://dx.doi. org/10.1109/TEM.1983.6448606.

Saaty, T. (2008). Decision making with the analytic hierarchy process. International Journal of Services Sciences, 1(1), 83-98. http:// dx.doi.org/10.1504/IJSSCl.2008.017590.

Sabattini, L., Cardarelli, E., Digani, V., Secchi, C., Fantuzzi, C., \& Fuerstenberg, K. (2015). Advanced sensing and control techniques for multi AGV systems in shared industrial environments. In Emerging Technologies \& Factory Automation 2015 proceedings of the international conference in Luxembourg (pp. 1-7). USA: IEEE Piscataway. http://dx.doi.org/10.1109/ETFA.2015.7301488.

Sellitto, M. A. (2018). Assessment of the effectiveness of green practices in the management of two supply chains. Business Process Management Journal, 24(1), 23-48. http://dx.doi.org/10.1108/BPMJ-03-2016-0067. https://doi.org/10.1108/BPMJ-03-2016-0067.

Sellitto, M., Borchardt, M., Pereira, G., \& Gomes, L. (2012). Environmental performance assessment of a provider of logistical services in an industrial supply chain. Theoretical Foundations of Chemical Engineering, 46(6), 691-703. http://dx.doi.org/10.1134/ S0040579512060206.

Shivanand, H., Benal, M., \& Koti, V. (2006). Flexible manufacturing system. Bangalore: New Age International Publishers.

Stevenson, M., \& Spring, M. (2007). Flexibility from a supply chain perspective: definition and review. International Journal of Operations \& Production Management, 277), 685-713. http://dx.doi.org/10.1108/01443570710756956.

Tao, F., Cheng, Y., Zhang, L., \& Nee, A. (2017). Advanced manufacturing systems: socialization characteristics and trends. Journal of Intelligent Manufacturing, 28(5), 1079-1094. http://dx.doi.org/10.1007/s10845-015-1042-8.

Tracey, M., Vonderembse, M., \& Lim, J. (1999). Manufacturing technology and strategy formulation: keys to enhancing competitiveness and improving performance. Journal of Operations Management, 174), 411-428. http://dx.doi.org/10.1016/S0272-6963(98)00045-X

Tzeng, G., \& Huang, C. (2012). Combined DEMATEL technique with hybrid MCDM methods for creating the aspired intelligent global manufacturing \& logistics systems. Annals of Operations Research, 1971), 159-190. http://dx.doi.org/10.1007/s10479-010-0829-4.

Vargas, L. (1982). Reciprocal matrices with random coefficients. Mathematical Modelling, 3(1), 69-81. http://dx.doi.org/10.1016/02700255(82)90013-6.

Voss, C., Tsikriktsis, N., \& Frohlich, M. (2002). Case research in operations management. International Journal of Operations \& Production Management, 22(2), 195-219. http://dx.doi.org/10.1108/01443570210414329.

Wabalickis, R. (1988). Justification of FMS with the analytic hierarchy process. Journal of Manufacturing Systems, 7(3), 175-182. http:// dx.doi.org/10.1016/0278-6125(88)90002-7.

Wang, X., Wang, L., Mohammed, A., \& Givehchi, M. (2017). Ubiquitous manufacturing system based on cloud: a robotics application. Robotics and Computer-integrated Manufacturing, 45(1), 116-125. http://dx.doi.org/10.1016/j.rcim.2016.01.007.

Ward, P., McCreery, J., Ritzman, L., \& Sharma, D. (1998). Competitive priorities in operations management. Decision Sciences, 29(4), 1035-1046. http://dx.doi.org/10.1111/j.1540-5915.1998.tb00886.x.

Yamamoto, H., Yamada, T., \& Tanaka, S. (2016). Moving robots lies and their minds with degree of confidence in a decentralized autonomous FMS. Journal of Robotics Networking and Artificial Life, 3(1), 61-64. http://dx.doi.org/10.2991/jrnal.2016.3.1.14.

Yazdani, M., Zarate, P., Coulibaly, A., \& Zavadskas, E. (2017). A group decision making support system in logistics and supply chain management. Expert Systems with Applications, 88(1), 376-392. http://dx.doi.org/10.1016/j.eswa.2017.07.014.

Zavadskas, E., \& Turskis, Z. (2011). Multiple criteria decision making (MCDM) methods in economics: an overview. Technological and Economic Development of Economy, 17(2), 397-427. http://dx.doi.org/10.3846/20294913.2011.593291.

Zhang, Q., Vonderembse, M., \& Cao, M. (2009). Product concept and prototype flexibility in manufacturing: implications for customer satisfaction. European Journal of Operational Research, 194(1), 143-154. http://dx.doi.org/10.1016/j.ejor.2007.12.013. 